\title{
Management of acute renal failure secondary to a renal infarction and renal thrombosis in a monorenal 76-year- old patient
}

\author{
Romaniouk I*, Orti I, Martinez A, , Mravcova M, Sanchez B, Gonzales B, Aparicio M, Borras R, Ribes J, Aznar Y, Blanco Y, Bea E, Graña J, \\ Gonzalez $B$ and Candel $M$ \\ Department of Nephrology, University Hospital of Ribera, Valencia, Spain
}

\begin{abstract}
Kidney infarction is a rare pathology with a low incidence registered, however it is most likely that the real incidence is quite higher because many cases are not diagnosed. The clinical presentation varies from nausea to a complete kidney failure when involves most of the parenchyma, therefore affecting the proper kidney function. As for the treatment several option might be considered. The in-situ artery thrombosis is one of the best options followed by anticoagulation or endovascular therapy. There are no standard options for a monorenal patient facing the pathology described, especially with an unsuspected final diagnose is involved.
\end{abstract}

\section{Introduction}

A Renal infarction is not a common pathology, the incidence of this disease varies from 0.7 to 1.4 percent [1]. Nevertheless, this complication is underdiagnosed and under-reported phenomenon, and needs to be diagnosed rapidly to prevent permanent loss of renal function. Renal infarction should be considered in the initial differential diagnosis of nephrolithiasis and pyelonephritis. It might be confused with urinary tract affections therefore; it is probable that the real incidence might be higher. The clinical presentation varies from a silent one in a relation to a small infarction to more florid clinical presentation including nausea, vomiting, pain in the lumbar fossa, fever, leukocytosis and marked elevation of lactic dehydrogenase (LDH) [2-4]. The Renal function may or may not be affected, being most frequent a transient elevation of plasma urea and creatinine. The treatment for renal infarction due to thromboembolism, is mainly in-situ artery thrombosis. Sometimes a renal artery dissection might be performed, but there is a lack of comparative studies to define a standard procedure. Other reports suggest an approach including anticoagulation or endovascular therapy $[5,6]$. As for treatment options, if the source is thromboemboli, in-situ thrombosis is the best option [7]. In other cases, patients with a prolonged ischemia and that might have formed a collateral circulation aggressive therapy will reduce the potential benefits of correcting the renal artery occlusion [8-10]. The situation changes when facing a monorenal patient. We present a clinical case of a monorenal 76-yearold patient with acute renal failure secondary to left renal thrombosis and renal ischemia.

\section{Case report}

A 76 year old Spanish female patient presented to the Emergency Department because of oligoanuria of several days of evolution, nausea and weakness. She referred similar episodes in the pass 6 month, medicated with furosemide by a general practitioner. As for medical background the patient was diagnosed with Diabetes Mellitus type 2, Osteoporosis and non-specific thrombocytosis followed up by Hematology.
Laboratory Examination showed: serum creatinine $7.6 \mathrm{mg} /$ $\mathrm{dl}$, sodium $140 \mathrm{mEq} / \mathrm{l}$, potassium $6.7 \mathrm{mEq} / \mathrm{L}$, leucocytes $8700 \mathrm{~mm}^{3}$, hemoglobin of $10.5 \mathrm{mg} / \mathrm{dl}$. Ultrasound showed right renal kidney atrophy $(6.7 \mathrm{~cm})$, left kidney $10.3 \mathrm{~cm}$ with normal cortical thickness and non-dilated urinary tract. Due to anuria so no urinary sample could be extracted. The patient started of hemodialysis slightly improving the clinical analysis. Negative serology. A further autoimmunity analyses showed negative ANAS, ANCAS, DNA, and anti GBM as well as negative tumor markers. After several days no improvement in renal function is seen as well as a persistent anuria. A CT scan was performed showing aortoiliac atheromatosis with left renal artery renal artery thrombosis, renal hypoperfusion and left polar infarcts as well as an atrophic right kidney (Figure 1). The case was discussed with radiology deciding to perform a mechanic thrombectomy improving slightly the perfusion of the left kidney. A stenosis zone was identified in the ostium of the renal artery and it is decided to be treated by angioplasty with a $5 \times 20 \mathrm{~mm}$ diameter Mustang balloon.

Unfortunately, 24 hours later the patient complicated with hemorrhagic shock performing an urgent nephrectomy with a transfer to the intensive care unit switching to continue venous hemodialysis until the clinical improvement. The patient complicated with an Enterococcus Faecalis Sepsis. After several days of improvement after antibiotic treatment a severe abdominal pain appears, a new CT scan revels an acute perforated cholecystitis needing a new surgical intervention. Finally, the patient transferred to nephrology, a new study showed the presence of lupus anticoagulant. Finally, the patient is discharged and continuing on hemodialysis.

${ }^{*}$ Correspondence to: Igor Romaniouk, Department of Nephrology, University Hospital of Ribera, Valencia, Spain, E-mail: igor9843@gmail.com

Key words: renal infarction, monorenal patients, in-situ thrombosis, endovascular therapy

Received: July 19, 2020; Accepted: August 10, 2020; Published: August 13, 2020 


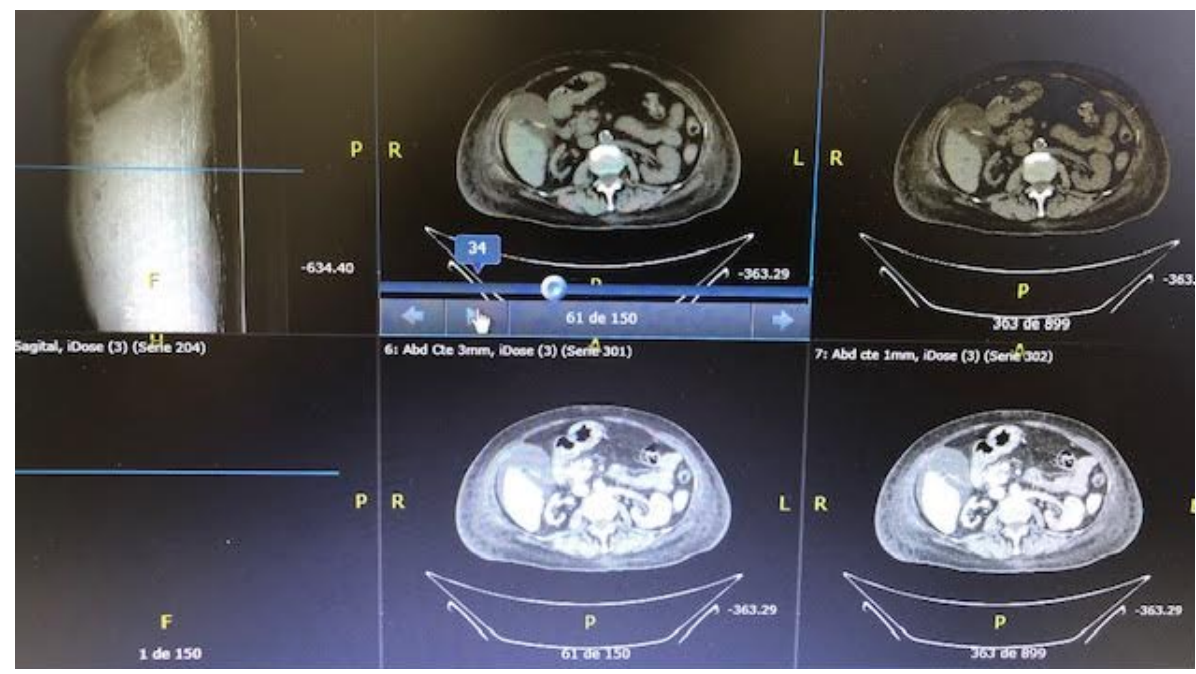

Figure 1. Right atrophic kidney and left renal thrombosis and renal infarction areas

\section{Discussion and Conclusion}

The renal infarction is a not a common pathology [11]. The main causes of a renal infarction are thromboemboli with heart thrombi as an origin and an in-situ thrombosis causing an occlusion of a branch or a main renal artery. In this clinical case, the echocardiogram was normal, therefore the source of the infarction and thrombosis should be other [12]. The average age differed depending on the underlying etiology: cardiogenic (65 years), renal artery injury (43 years), hypercoagulable state (62 years), and idiopathic ( 49.5 years). Patients in the cardiogenic group tend to have a history of hypertension, cardiovascular disease (CVD), diabetes mellitus, heart valve disease, and atrial fibrillation than their counterparts from the other group [13]. The clinical presentation in this case is not a typical one. The patient consulted for an anuria and severe wickless, suggesting and advance stage of an underlying pathology, the ultrasound revealed right renal atrophy but no suggesting images of infarction nor thrombosis, blood test was clear for an acute renal failure. Considering the age of the patient an autoimmune disease was ruled out. The CT scan showed a thrombosis and renal infarction in a monorrenal patient, it is logical to consider an aggressive option to save the only functional kidney that the patient had, however, and after overcoming all the complication lupus anticoagulant appeared suggesting anti phospholipid syndrome, that might cause a pro coagulant state explaining the clinical state suffered by this patient.

As for the treatment options, if the source is a thromboemboli, insitu thrombosis is the best option [14]. Patients with an acute renal artery occlusion, a percutaneous endovascular therapy might be the best choice, in this case both procedures were performed leading to a hemorrhagic shock. In other cases, patients with a prolonged ischemia and that might have formed a collateral circulation aggressive therapy will reduce the potential benefits of correcting the renal artery occlusion, this was not the case. Prolonged ischemia also reduces the likelihood that there will be viable tissue, therefore an anticoagulation might be good treatment option but, in this case, considering that only one kidney was functional, an aggressive treatment was the best choice.

A prognosis depends on mainly of the cause and the patient morbidity; however, an early diagnosis and treatment is more beneficial for all groups of patients.

\section{References}

1. Caravaca-Fontán F, Pampa Saico S, Elías Triviño S, Galeano Álvarez C, Gomis Couto A, et al. (2016) Acute renal infarction: Clinical characteristics and prognostic factors. Nefrologia 36: 141-148.

2. Piccoli GB, Priola AM, Vigotti FN, Guzzo G, Veltri A (2014) Renal infarction versus pyelonephritis in a woman presenting with fever and flank pain. Am J Kidney Dis 64: 311-314.

3. Kozsets Z, Plotkin E, Bernheim J, Zissin R (2002) The clinical spectrum of renal infarction. Isr Med Assoc J 4: 781-784.

4. Bae EJ, Hwang K, Jang HN, Kim MJ, Jeon DH, Kim HJ, et al. (2014) A retrospective study of short- and long-term effects on renal function after acute renal infarction. Ren Fail 36: 1385-1389.

5. Lin WL, Seak CJ, Wu JY, Weng YM, Chen HC (2014) Risk factors for development of chronic kidney disease following renal infarction: Retrospective evaluation of emergency room patients from a single center. PLoS One 9: 9888.

6. Chu PL, Wei YF, Huang JW, Chen SI, Chu TS, et al. (2006) Clinical characteristics of patients with segmental renal infarction. Nephrology 11: 336-340.

7. Hoxie HJ, Coggin CB (1940) Renal infarction: statistical study of two hundred and five cases and detailed report of an unusual case. Arch Intern Med 65: 587-594.

8. Paris B, Bobrie G, Rossignol P, Le Coz C, Chedid A, et al. (2006) Blood pressure and renal outcomes in patients with kidney infarction and hypertension. J Hypertens 24: 1649-1654.

9. Frost L, Engholm G, Johnson S, Moller H, Henneberg EW, et al. (2001) Incident thromboembolism in aorta and the renal, mesenteric, pelvic, and extremity arteries after discharge from hospital with a diagnosis of atrial fibrillation. Arch Intern Med 161: 272-276.

10. Antopolsky M, Simanovsky N, Stalnikowicz R, Salameh S, Hiller N (2012) Renal infarction in the ED: 10-year experience and review of the literature. Am J Emerg Med 30: $1055-1060$.

11. Bolderman R, Oyen R, Verrijcken A, Knockaert D, Vanderschueren S (2006) Idiopathic renal infarction. Am J Med 119: 356e9-356e12.

12. Bae EJ, Hwang K, Jang HN, Kim MJ, Jeon DH, et al. (2014) A retrospective study of short- and long-term effects on renal function after acute renal infarction. Ren Fail 36: 1385-1389.

13. Hazanov N, Somin M, Attali M, Beilinson N, Thaler M, et al. (2004) Acute renal embolism. Forty-four cases of renal infarction in patients with auricular auricular fibrillation. Medicine 83: 292-299.

14. Steckel A, Johnston J, Fraley DS, Bruns FJ, Segel DP, et al. (1984) The use of streptokinase to treat renal artery thrombolism. Am J Kidney Dis 4: 166-170.

Copyright: (C2020 Romaniouk I. This is an open-access article distributed under the terms of the Creative Commons Attribution License, which permits unrestricted use, distribution, and reproduction in any medium, provided the original author and source are credited. 